PontifícIa UniversidAde CATÓLICA do RIO dE JANEIRO

\title{
Mudanças nas Rotinas Organizacionais: o impacto no atendimento aos clientes do Itaú Unibanco S.A.
}

Giuliana Carolina Rosa Mota

Trabalho de Conclusão de Curso

Centro de CiênCIAS SOCIAIS - CCS

Departamento de Administração

Graduação em Administração de Empresas

Rio de Janeiro, dezembro de 2019. 
Giuliana Carolina Rosa Mota

Mudanças nas Rotinas Organizacionais: o impacto no atendimento aos clientes do Itaú Unibanco S.A.

Trabalho de Conclusão de Curso

Trabalho de Conclusão de Curso, apresentado ao programa de graduação em Administração da PUC-Rio como requisito parcial para a obtenção do título de graduação em Administração.

Orientadora: Maria Isabel Guimarães.

Rio de Janeiro, dezembro de 2019. 


\section{Agradecimentos}

Primeiramente, gostaria de agradecer à minha mãe, que é a luz da minha vida, Eliana Mota, que, além de se desdobrar para ver o meu sucesso, sempre ofereceu todo apoio em termos emocionais.

À PUC-Rio, que me proporcionou tanto conhecimento e me fez conhecer pessoas incríveis que aguentaram diversos episódios comigo nesses cinco anos de crescimento. Em especial à Sharon Paskin e Manuella Gomes, que tanto fizeram para me ajudar nesta reta final, e aos meus amigos Joao Paulo, Angélica e Susana.

Aos professores que me ajudaram nessa trajetória incrível, onde aprendi muito e cresci profissionalmente. À Mariana Viana, minha amiga que me ajudou muito no começo desta trajetória e me fez continuar mesmo quando eu queria desistir.

À minha orientadora, Isabel Guimarães, que me proporcionou uma experiência inovadora me aproximando do empreendedorismo, além de toda a ajuda para construção deste trabalho.

A todos que me acompanharam ao longo da minha vida e a Deus que me guia pelos seus caminhos. 


\section{Resumo}

Mota, Giuliana Carolina Rosa. Mudanças nas Rotinas Organizacionais: o impacto no atendimento aos clientes do Itaú Unibanco S.A. Rio de Janeiro, 2019. Trabalho de conclusão de curso - Departamento de Administração. Pontifícia Universidade Católica do Rio de Janeiro.

$\mathrm{Na}$ atualidade, percebemos que as mudanças nos processos organizacionais têm se intensificado, para cada vez mais se adequar às demandas dos clientes. Esse fenômeno acontece devido às organizações aspirarem vantagens competitivas no mercado em que estão inseridas. Em virtude dessas mudanças, este estudo busca, por meio de uma pesquisa exploratória qualitativa, entender de que forma se dá a aprendizagem dos novos processos e o impacto da mudança no atendimento aos clientes - nesse caso, os clientes do Banco Itaú S.A.

Foram entrevistados vinte funcionários das agências do centro do Rio de Janeiro, da área operacional, com os cargos de caixa, supervisor e gerente. A partir da análise das entrevistas, percebeu-se que as mudanças nos processos do Itaú têm grande impacto no atendimento aos clientes. Na percepção da maioria dos funcionários, a aprendizagem de uma nova rotina se dá no dia a dia, mesmo com a oferta de cursos e materiais acerca do novo processo.

Palavras chave: Mudanças Organizacionais; Aprendizagem; Impacto no atendimento; Banco Itaú. 
Abstract

Mota, Giuliana Carolina Rosa. Changes in Organizational Routines: learning and the impact on customer service at Itaú Bank S.A. Rio de Janeiro, 2019. Conclusion work - Department of Business Administration. Pontifical Catholic University of Rio de Janeiro.

Nowadays, we realize that the changes in the organizational processes have been intensifying, to increasingly adapt to the demands of customers. This phenomenon happens because organizations aspire to competitive advantages in the market which they operate. Due to these changes, this study seeks, through qualitative exploratory research, to understand how the new processes are learned and the impact of change in customer service - in this case, Itaú Bank S.A. Twenty employees from the central area of Rio de Janeiro were interviewed, with the positions of cashier, supervisor and manager. From the analysis of the interviews, it was noticed that changes in Itaú's processes have a great impact on customer service. In the opinion of most employees, learning a new routine takes place on a daily basis, even with courses and materials offered about the new process.

Keywords: Organizational Changes; Learning; Impact on attendance; Itau bank. 


\section{Sumário}

1. Introdução 1

1.1. Objetivo do estudo 1

1.2. Objetivos intermediários 1

1.3. Delimitação do estudo 2

1.4. Relevância do estudo 2

2. Referencial Teórico 4

2.1. O conceito de rotinas organizacionais 4

2.2. Aprendizagem organizacional 7

2.3. Atendimento ao público 9

3 . Métodos e procedimentos de coleta e de análise de dados do estudo11

3.1. Métodos de pesquisa utilizados 11

3.2. Procedimentos e instrumentos de coleta de dados utilizados no $\begin{array}{ll}\text { estudo } & 11\end{array}$

3.3. Formas de tratamento e análise dos dados coletados para o estudo12

3.4. Limitações do método

4. Apresentação e análise dos resultados

5. Considerações Finais

6. Referências Bibliográficas 
Índice de ilustrações

\section{Figura}

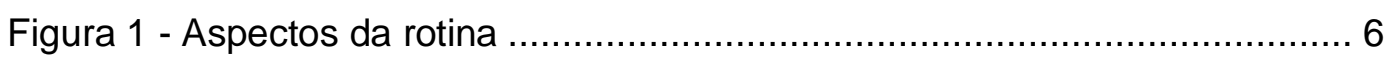

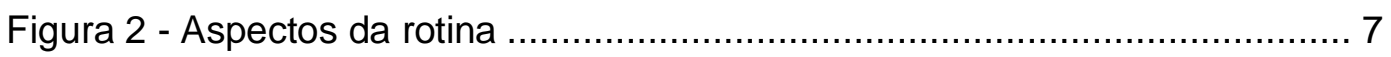

\section{Quadros}

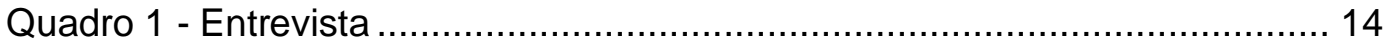

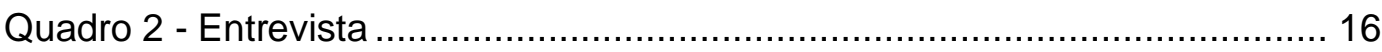

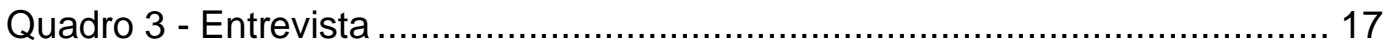

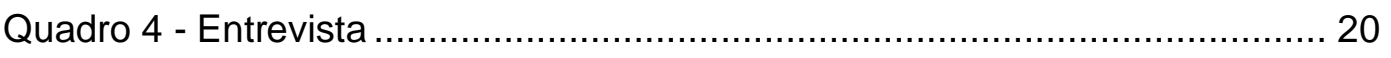




\section{Introdução}

\section{Tema e Problema de Estudo:}

A cada dia o mundo vem se atualizando com relação a globalização e tecnologia, e como consequência as pessoas ficam mais dependentes e exigem mais sobre a inserção desses avanços (FANTINI \& OLIVEIRA, 2011). Apesar disso, as empresas não tiveram tempo de se atualizar e acabaram tratando os funcionários apenas como utensílios para que esses maximizassem o valor da empresa, gerando mais lucro para os acionistas (BARRETO, 2006; FABRICIO, 2012; HELOANI, 2004). Como consequência, os colaboradores passaram a encarar a atividade laboral como uma atividade recompensadora, deixando para trás o compromisso com as normas padrão de como agir com o cliente, afetando assim a qualidade do serviço prestado (BRAVERMAN, 1987).

O problema deste estudo está relacionado ao impacto que as mudanças da rotina do dia a dia do Banco Itaú têm sobre o atendimento aos clientes. Tais mudanças afetam negativamente a rotina do Banco, tornando-as mais burocráticas, dificultando 0 atendimento quando se fala em mudanças legislativas, como, por exemplo, a necessidade em notificar o Banco Central quanto a valores acima de determinado valor. Elas também afetam positivamente, quando se fala em nova tecnologia, agilizando o atendimento. $\mathrm{O}$ Banco Itaú está cada vez mais adepto às mudanças, para melhorar a forma de atender e captar cada vez mais clientes, de acordo com o feedback positivo.

\subsection{Objetivo do estudo}

Este trabalho tem como objetivo identificar de que maneira as mudanças nas rotinas organizacionais afetam o atendimento aos clientes do Banco Itaú.

\subsection{Objetivos intermediários}

Para ajudar a atingir o objetivo principal do estudo, é importante salientar os objetivos intermediários, como: 
I. Identificar quais são as rotinas organizacionais relacionadas ao atendimento ao cliente;

II. Entender por que se dá o processo de mudança dessas rotinas;

III. Entender como ocorre a aprendizagem das novas rotinas; e

IV. Entender, após a mudança, de que maneira os clientes são afetados.

\subsection{Delimitação do estudo}

Para que o estudo possa cumprir seu objetivo, se faz necessário a delimitação do estudo. Segundo Magalhães e Orquiza (2002, p.19), "delimitar o assunto é fixar sua extensão, abrangência e profundidade".

O presente estudo foi realizado com funcionários das agências do Banco Itaú, localizadas na cidade do Rio de Janeiro - 0417- Rio Itamarati; 0477- Rio Cinelândia; 0706 - Rio Catete; 6197- Rio Buenos Aires; 6157- Rio Senador Dantas; 6196 - Rio Mayrink Veiga; 8097- Rio Uruguaiana; e 3032 - Rio Nova Rio Branco. Os funcionários entrevistados ocupam os cargos de caixa, supervisor e gerente na área operacional, com no mínimo de cinco anos atuando nesse segmento.

\subsection{Relevância do estudo}

O mundo muda a cada dia, estando sempre em desenvolvimento, e assim também é com o mundo corporativo, que se adapta a novas necessidades e tendências. A cada dia, mais os clientes estão prezando pelo bom atendimento, e as empresas precisam se adaptar a essa nova realidade. Para obter sucesso, as organizações precisam ter os seus processos muito bem definidos e eficientes.

Tal estudo mostra-se relevante para as empresas, principalmente, nesse caso, as situadas no setor bancário. Em virtude do impacto que as mudanças nas rotinas organizacionais têm sobre o atendimento aos clientes, uma vez que um atendimento de qualidade é cada vez mais exigido, as empresas precisam estar preparadas para tal feito, para garantir vantagens competitivas frente aos seus concorrentes. 
Apresenta relevância, também, para pesquisadores que visam a compreender esse fenômeno de mudanças em rotinas organizacionais, no setor bancário. 


\section{Referencial Teórico}

A revisão de literatura, realizada para construção deste referencial teórico, tem como base conceitos relacionados às rotinas organizacionais, aprendizagem e atendimento ao público.

\subsection{O conceito de rotinas organizacionais}

As rotinas organizacionais podem ser definidas como padrões de comportamento repetitivo inseridas pela empresa para corroborar seus objetivos e práticas do dia a dia. São criadas para solucionar problemas dentro da organização e apresentam poucas variações entre uma interação e outra (SAMPAIO, 2016).

É possível dizer que as organizações respondem às tarefas já estabelecidas por meio de suas rotinas, e isso traz uma estabilidade e mais eficiência ao negócio, operando assim de uma maneira semiautomática (SAMPAIO, 2016).

Feldman (2013) enfatiza "a importância da atuação dos indivíduos, da subjetividade, da improvisação, e da capacidade de refletir sobre desempenhos passados na construção de novas rotinas" (p. 7, apud SAMPAIO, 2016).

Feldman e Pentland (2003) apresentam uma definição de rotinas organizacionais baseada em teorias da estruturação e da prática. Eles argumentam que para ser uma rotina organizacional deve exibir "padrões repetitivos, reconhecíveis, de ações interdependentes, realizadas por múltiplos atores" (FELDMAN; PENTLAND, 2003, apud SAMPAIO, 2016). Estas condições são necessárias para que o fenômeno seja uma rotina, caso falte algum, não deveria ser caracterizado como rotina organizacional.

As rotinas organizacionais são constituídas por dois aspectos, que constituem a sua dinâmica interna: o aspecto performativo e o aspecto ostensivo. Enquanto o aspecto performativo pode ser visto como a rotina na 
prática, o ostensivo é a rotina na ideia. "O aspecto ostensivo de uma rotina é a ideia abstrata e generalizada da rotina, enquanto o performativo consiste em ações específicas, em locais específicos, horários específicos e por pessoas específicas" (GUIMARÃES, 2018, p. 45).

As rotinas, por vezes, são confundidas com objetos ou coisas, o que pode trazer a esse conceito uma percepção errada, uma vez que são confundidas com seus artefatos (formulários, sistemas, normas, fluxogramas etc.) (GUIMARÃES, 2018).

Rotinas organizacionais não são padrões fixos e acabados, mas estão sempre em transformação e não podem ser reproduzidas. Ao contrário, são definidas de acordo com os padrões de ação com base no julgamento local e improvisação dos envolvidos (SAMPAIO, 2016).

Outra característica das rotinas é o seu caráter coletivo. A rotina pode ser conduzida por vários atores em diferentes lugares. Portanto, as rotinas podem ser distribuídas dentro de uma organização, mas os atores estarão ligados por suas interações (DOSI et al., 2000).

Pode-se destacar, também, o grau de consciência envolvido na execução das rotinas organizacionais. Becker (2004) "identifica grande divergência de opiniões na literatura entre as posições de que as rotinas são processos inconscientes ou ao contrário, esforços conscientes" (p. 6, apud NOGUEIRA, 2010). Em relação à primeira posição, os indivíduos executam as rotinas sem dedicar atenção e, com isso, não utilizam recursos cognitivos relacionados à consciência. Já no segundo caso, as rotinas representam esforços para o cumprimento de determinados resultados (SPULDARO, 2013).

$\mathrm{Na}$ figura 1- Aspectos da rotina são possíveis entender como Feldman (2016) caracteriza cada aspecto constituinte da rotina organizacional: 


\title{
Figura 1 - Aspectos da rotina
}
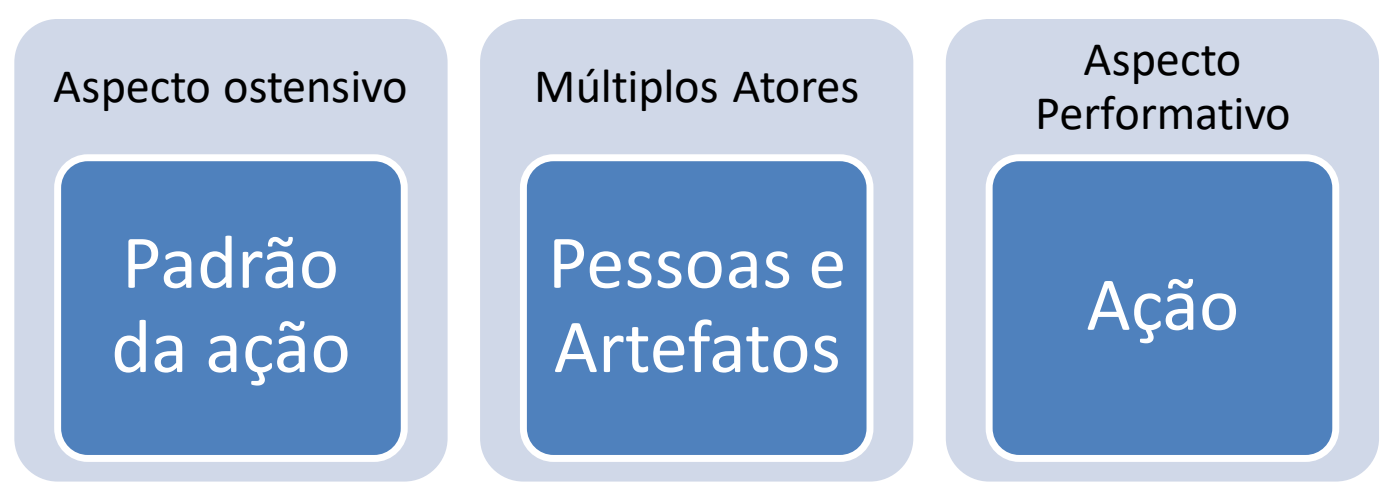

Fonte: A autora, inspirada em Guimarães, 2018.

\begin{abstract}
"Os padrões abstratos que os participantes usam para orientar, explicar e referir-se a performances específicas da rotina". (PENTLAND e FELDMAN, 2005, p. 795. Tradução livre; p.45, apud GUIMARÃES, 2012).
\end{abstract}

As rotinas organizacionais possuem uma dinâmica entre os três elementos - aspecto ostensivo, aspecto performativo e artefatos (FELDMAN; PENTLAND, 2003; PENTLAND; FELDMAN, 2005; p.48, apud GUIMARÃES, 2018), que podem ser entendidas através da figura 2: 
Figura 2 - Aspectos da rotina

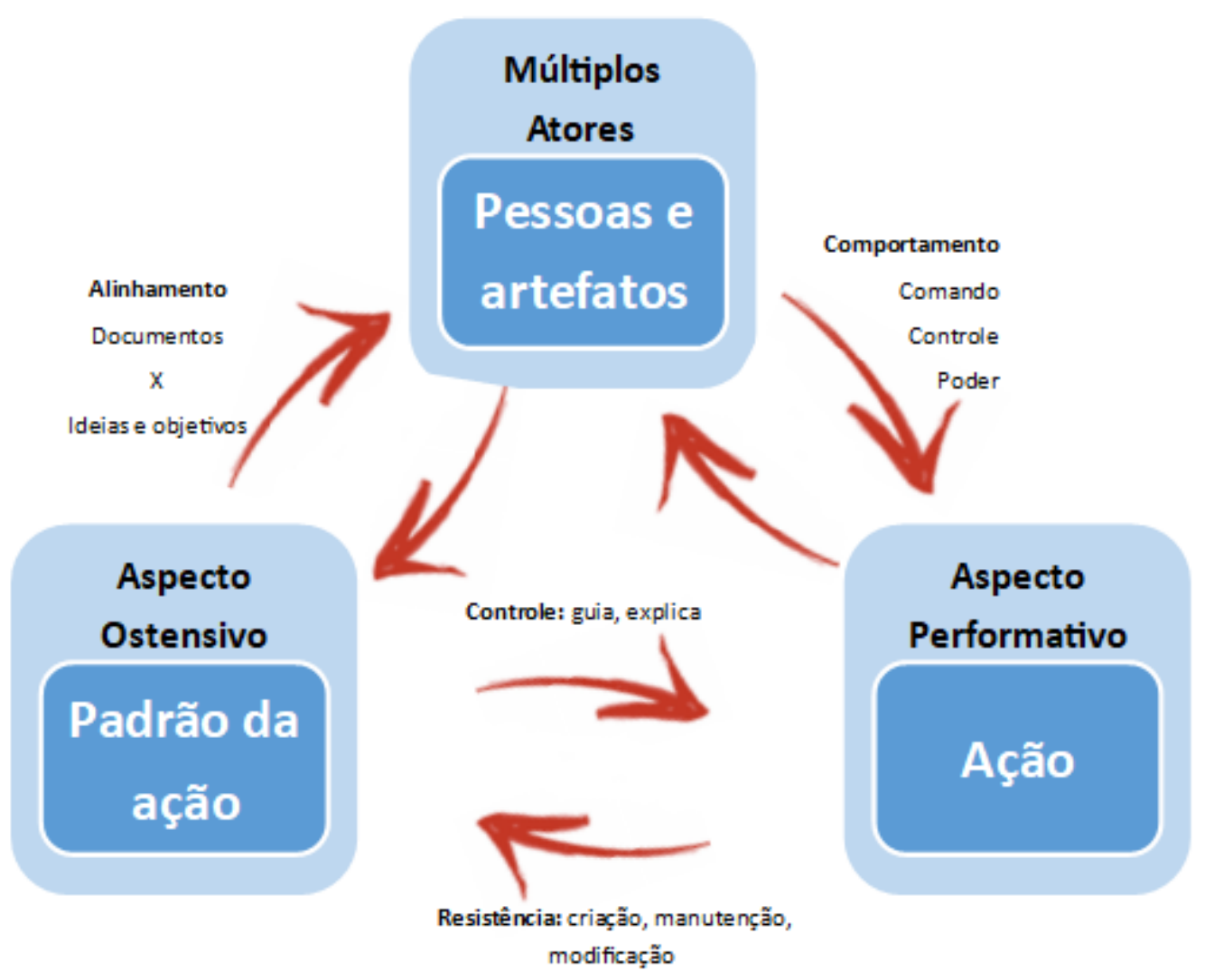

Fonte: A autora, inspirada em Guimarães, 2018.

A relação entre os aspectos ostensivo e performativo pode ser mudada de acordo com a interação entre eles, o que ocasiona uma mudança de desempenho, resultando em várias possibilidades de uma mesma rotina. Essa dinâmica, que envolve movimentos de estabilidade ou mudança, pode estar associada à aprendizagem que ocorre nas rotinas (GUIMARAES, 2018).

\subsection{Aprendizagem organizacional}

A aprendizagem organizacional se relaciona ao desenvolvimento de novas competências e aquisições de conhecimentos que agreguem valor ao dia a dia do colaborador, para assim trazer maior informação no âmbito profissional, bem como obter os conhecimentos necessários para nortear suas habilidades na execução das tarefas do cotidiano (PONTES, 2018). 
De acordo com GUNSS (1998), existem sete aprendizagens, que serão descritas a seguir:

I. Aprendizagem de tarefas - direcionada para a execução de papéis prédeterminados.

II. Aprendizagem sistêmica - consiste na aquisição de conhecimentos coletivos, além de individuais. Desta forma, obtendo o domínio de determinadas atividades, é possível compreender o momento e a maneira como ocorrem os gaps.

III. Aprendizagem cultural - fundamentado no plano estratégico, com base na cultura organizacional, missão, visão e valores da empresa. $O$ comportamento dos gestores se baseia nestes aspectos, fazendo com que resulte na transmissão dos processos aos seus colaboradores para que estes aprendam através da observação.

IV. Aprendizagem de liderança - baseado nas ações dos líderes, através de seus exemplos, os colaboradores passam a executar as tarefas espelhando o comportamento adquiridos através da percepção apresentada. Quanto maior a abertura para disseminação do conhecimento, maior o aprendizado adquirido.

V. Aprendizagem por compartilhamento - ocorre em situações onde o funcionário contempla as novas habilidades e técnicas, transmitindo adiante os conhecimentos. Esta aprendizagem é uma das mais usuais, já que oferece uma compreensão significativa e diversa ao realizar determinada atividade.

VI. Aprendizagem ativa - Sendo a mais presente no cotidiano, ela se dá a partir de atividades desempenhadas comumente, atualizando os conhecimentos prévios, a fim de aperfeiçoar as tarefas.

VII. Aprendizagem por experiências profissionais - o profissional adquire insumos de acordo com a vivência no ambiente de trabalho, sejam elas boas ou ruins. De acordo com essa percepção, o funcionário assimila suas ações e modifica sua abordagem com o cliente para que evite o desempenho de atitudes equivocadas e melhor atendê-los. 


\subsection{Atendimento ao público}

No atendimento ao público, a satisfação do cliente é importante para a empresa obter resultados positivos e aumentar os seus lucros, reconhecendo os clientes como importante ativo. A priorização da qualidade e excelência deve estar entre os princípios da empresa, assim como a satisfação que está diretamente ligada à percepção que ele tem da empresa, seja positiva ou negativa.

As empresas estão em um mercado competitivo e é preciso que elas superem as expectativas dos clientes, fazendo-os se sentirem satisfeitos para retê-los e superar a concorrência. Os colaboradores precisam sempre tratar o cliente da melhor forma, com educação e simpatia, passando confiança para eles se fidelizarem ao banco. A organização deve estar sempre buscando atualizações sobre o mercado e realizando treinamentos para deixar seus colaboradores mais capacitados, atendendo assim todas as dúvidas e demandas do cliente (KOTLER, 2000).

$\mathrm{Na}$ visão de Chiavenato (2000, p. 209), o cliente é o principal objetivo do negócio, pois através dele que se cria valor e a empresa se destaca perante a concorrência para tal feito, a organização precisa estar cada vez mais disposta a entender as necessidades dos clientes e ouvi-los para conseguir supri-las.

Um dos componentes da qualidade é atender as exigências dos clientes, como ouvi-los e ajudá-los em sua demanda. A qualidade do atendimento que é oferecido pode determinar o sucesso ou o fracasso de um negócio, por isso é necessário ter funcionários bem treinados para que o contato com o cliente seja satisfatório, tendo em vista que essa questão influencia diretamente no relacionamento (KOTLER, 1991).

Os clientes gostam de ser chamados pelo nome, pois assim há uma maior aproximação dele com o colaborador, traçando laços de amizade, confiabilidade, fidelidade e fazendo-os se sentirem especiais. Isso se dá partir de diversas atividades, como a facilitação de solução de demandas, cobrança, créditos, renegociações de dívidas, dentre outras vantagens que podem encantar 0 cliente (ELTZ, 1994). 
Las Casas (1999) defende que um bom atendimento é observado a partir do desempenho do profissional que ao prestar bons serviços, por isso a qualificação do colaborador tem influência na forma de abordagem ao cliente, por isso a importância de ter funcionários bem treinados e eficientes. Os treinamentos são muito importantes para deixar os funcionários cada vez mais capacitados para melhor atender aos clientes. 


\section{Métodos e procedimentos de coleta e de análise de dados do estudo}

\subsection{Métodos de pesquisa utilizados}

Segundo Roberto Pinheiro (2004), a pesquisa qualitativa é indicada quando se deseja uma análise de um determinado assunto de forma mais profunda, buscando um melhor entendimento sobre ele.

Trata-se de um estudo teórico-empírico, baseado em estudos bibliográficos e conceitos retirados de artigos e trabalhos acadêmicos, além de um estudo de campo, baseado em entrevistas, coletando dados significativos para este trabalho. O roteiro das perguntas foi semiestruturado, com perguntas abertas para que se pudesse captar de forma fidedigna a percepção que o entrevistado tem acerca do tema deste estudo.

\subsection{Procedimentos e instrumentos de coleta de dados utilizados no estudo}

A coleta de dados se deu através da realização de vinte entrevistas, com um roteiro semiestruturado (Apêndice). As entrevistas foram realizadas entre 15 de abril e 18 de outubro de 2019, no Rio de Janeiro. Todos os entrevistados são funcionários do Banco Itaú há pelo menos cinco anos, nas funções de caixa, supervisor e gerente na área operacional.

O objetivo das entrevistas foi entender de que forma as mudanças nas rotinas organizacionais afetam o atendimento aos clientes e como acontece a aprendizagem da rotina com relação às mudanças da parte dos colaboradores. Para isso, as entrevistas foram direcionadas a funcionários com mais tempo na função, para que essas mudanças pudessem ser percebidas. Nas entrevistas, os questionamentos foram acerca do impacto que essas mudanças têm sobre o atendimento e o porquê dá mudança ocorrer. 


\subsection{Formas de tratamento e análise dos dados coletados para o estudo}

Foi realizada uma análise do conteúdo das entrevistas, visando um melhor entendimento do assunto, para que o trabalho fosse concluído. Segundo Martins (2006, p. 87): "A análise de um estudo de caso deve deixar claro que todas as evidências relevantes foram abordadas e deram sustentação às proposições que parametrizaram toda a investigação".

\subsection{Limitações do método}

Segundo Vergara (2006, p. 61), "Todo método tem possibilidades e limitações". O método utilizado no presente trabalho não busca generalizações. Há uma possibilidade de tendenciosidade, visto que o pesquisador está relacionado diretamente com esse tema, já que trabalha em uma agência do Banco Itaú. A quantidade de entrevistados foi relativamente pequena, podendo haver algum viés nas informações.

Uma das limitações deste estudo é o fato das respostas dos entrevistados terem algum tipo de tendência influenciada pelo roteiro semiestruturado. Ademais, há também a possibilidade do entrevistado não ser totalmente honesto em suas repostas. 


\section{Apresentação e análise dos resultados}

Nesta seção, serão apresentados os resultados da pesquisa acerca do impacto que as mudanças nas rotinas organizacionais têm sobre $o$ atendimento aos clientes do Banco Itaú, a partir da realização de vinte entrevistas com roteiro semiestruturado, com funcionários do banco.

A seleção dos entrevistados permitiu o acesso a experiências vividas em diversos contextos, por um grupo de pessoas com diferentes características. Há três grandes grupos entre os entrevistados: gerentes operacionais, supervisores operacionais e caixas.

Para apresentação dos resultados, vale ressaltar que as perguntas das entrevistas (Anexo 1) foram estruturadas para entender as rotinas dos colaboradores do Itaú na área operacional, e de que forma as mudanças nas rotinas impactam no atendimento. Tais rotinas organizacionais (FELDMAN; PETLAND, 2003, p.95), se dão pelo padrão repetitivo e reconhecível de ações rotineiras, na prática, através de entregas de cartão, pagamento de boletos, notificação ao Banco Central de valores em espécie, transferência de valores altos que gera "remota" - autorização a ser feita pelo gerente da conta, tempo de fila, venda de produtos como seguros, capitalização, crédito consignado, crédito sem garantia e serviços de conveniência como biometria, senha eletrônica, vinculação de benefícios do INSS e debito automático.

A seguir, serão apresentados os quadros com a síntese das respostas a algumas das principais perguntas que norteiam essa pesquisa. As entrevistas foram realizadas individualmente e gravadas sempre que permitido pelo entrevistado. A partir do resumo e/ou transcrição de cada entrevista, foram elaborados os quadros presentes nessa seção.

As opiniões consolidadas dos colaboradores do Itaú conforme as perguntas descritas nos próprios quadros 1, 2, 3 e 4 . 


\section{Quadro 1 - Entrevista}

\begin{tabular}{|c|c|}
\hline Pergunta & $\begin{array}{l}\text { Você percebe mudanças na sua rotina do organizacional ao } \\
\text { longo dos anos, impactando o atendimento do cliente? }\end{array}$ \\
\hline $\begin{array}{l}\text { Entrevistado } \\
1\end{array}$ & $\begin{array}{l}\text { Sim, sempre há mudanças, principalmente quando há uma nova } \\
\text { tecnologia. }\end{array}$ \\
\hline $\begin{array}{l}\text { Entrevistado } \\
2\end{array}$ & $\begin{array}{l}\text { Sim, todos os dias têm novos procedimentos e regras para } \\
\text { atendimento. }\end{array}$ \\
\hline $\begin{array}{l}\text { Entrevistado } \\
3\end{array}$ & Sim, bastante. \\
\hline $\begin{array}{l}\text { Entrevistado } \\
4\end{array}$ & $\begin{array}{l}\text { Sempre, com as novas tecnologias e legislações precisamos } \\
\text { sempre mudar o atendimento. }\end{array}$ \\
\hline $\begin{array}{l}\text { Entrevistado } \\
5\end{array}$ & Sim, sempre. \\
\hline $\begin{array}{l}\text { Entrevistado } \\
6\end{array}$ & $\begin{array}{l}\text { Sim, o atendimento sempre muda, dependendo do foco de } \\
\text { atuação da empresa no momento. }\end{array}$ \\
\hline $\begin{array}{l}\text { Entrevistado } \\
7\end{array}$ & $\begin{array}{l}\text { Sim, sempre há novidades nos processos para atendimento ao } \\
\text { público. }\end{array}$ \\
\hline $\begin{array}{l}\text { Entrevistado } \\
8\end{array}$ & Sim, cada dia uma tecnologia e um novo processo. \\
\hline $\begin{array}{l}\text { Entrevistado } \\
9\end{array}$ & Sim, sempre mudando para melhor atender os clientes. \\
\hline $\begin{array}{l}\text { Entrevistado } \\
10\end{array}$ & $\begin{array}{l}\text { Sim, sempre tem mudanças para atender as necessidades dos } \\
\text { clientes. }\end{array}$ \\
\hline $\begin{array}{l}\text { Entrevistado } \\
11\end{array}$ & Sim, o processo está sempre mudando. \\
\hline $\begin{array}{l}\text { Entrevistado } \\
12\end{array}$ & Sim, sempre que recebemos novas regras de atendimento. \\
\hline $\begin{array}{l}\text { Entrevistado } \\
13\end{array}$ & $\begin{array}{l}\text { Sim, há mudanças nos processos internos e isso influencia no } \\
\text { atendimento. }\end{array}$ \\
\hline $\begin{array}{l}\text { Entrevistado } \\
14\end{array}$ & Sim, às vezes essas mudanças são constantes. \\
\hline $\begin{array}{l}\text { Entrevistado } \\
15\end{array}$ & Sim, os clientes sempre sofrem com mudanças internas. \\
\hline $\begin{array}{l}\text { Entrevistado } \\
16\end{array}$ & $\begin{array}{l}\text { Sim, os processos internos às vezes facilitam e às vezes } \\
\text { dificultam o atendimento. }\end{array}$ \\
\hline $\begin{array}{l}\text { Entrevistado } \\
17\end{array}$ & $\begin{array}{l}\text { Sim, há mudanças internas em curto espaço de tempo que } \\
\text { modifica o atendimento. }\end{array}$ \\
\hline $\begin{array}{l}\text { Entrevistado } \\
18\end{array}$ & $\begin{array}{l}\text { Sim, no dia a dia sempre muda os processos, o que acaba } \\
\text { refletindo no cliente. }\end{array}$ \\
\hline $\begin{array}{l}\text { Entrevistado } \\
19\end{array}$ & Sim, os processos e a tecnologia impactam no atendimento. \\
\hline
\end{tabular}


É importante destacar que, no Quadro 1, todos os entrevistados percebem mudanças na rotina organizacional para o atendimento aos clientes. Quando perguntados se percebiam mudanças na rotina organizacional em relação ao atendimento aos clientes, as respostas foram sempre "Sim". Isso nos mostra como a rotina dos processos da empresa afeta de forma direta o atendimento. A maioria dos entrevistados cita as mudanças como constantes e como melhoria na forma de atender o público - seja em quesitos de tecnologia ou regras ambos para suprir as necessidades e gerar feedbacks positivos dos clientes, melhorando a qualidade do atendimento.

De acordo com o Entrevistado 13, "O banco cada vez mais vem ficando digital e temos que nos adaptar às normas. Antigamente era tudo manual, hoje tudo está mais digital".

De acordo com o Entrevistado 2, "No banco, a tecnologia e as mudanças nas leis impactam diretamente $o$ atendimento, mudanças como, por exemplo, pagamento de boletos vencidos em qualquer banco".

Já o Entrevistado 15 disse: "Todas as mudanças internas, de algum modo, influenciam no atendimento, como por exemplo, a necessidade de cadastramento da biometria na entrega de cartão, que antes não era obrigatória. Isso atrasa $\mathrm{o}$ atendimento, tendo impacto direto no tempo de fila e na satisfação dos clientes".

É possível observar que as mudanças ocorrem, prioritariamente, em decorrência de novas leis, demandas de cliente, novas tecnologias e concorrência de empresas do mesmo setor - buscando sempre melhorar e aperfeiçoar o atendimento ao cliente, que é o foco do negócio. 
Quadro 2, está outra pergunta importante sobre o assunto pesquisado, com as respectivas respostas dos colaboradores, consolidando as opiniões de todos em relação às mudanças.

\section{Quadro 2 - Entrevista}

\begin{tabular}{|c|c|}
\hline Pergunta & $\begin{array}{l}\text { Essas mudanças nos processos interferem no atendimento? } \\
\text { Quais interferências você identifica? }\end{array}$ \\
\hline $\begin{array}{l}\text { Entrevistado } \\
1\end{array}$ & Sim, na rapidez do atendimento. \\
\hline $\begin{array}{l}\text { Entrevistado } \\
2\end{array}$ & Sim, na solução de demandas. \\
\hline $\begin{array}{l}\text { Entrevistado } \\
3\end{array}$ & Sempre, na agilidade do atendimento e solução de problemas. \\
\hline $\begin{array}{l}\text { Entrevistado } \\
4\end{array}$ & Às vezes sim, no tempo de atendimento. \\
\hline $\begin{array}{l}\text { Entrevistado } \\
5\end{array}$ & Sim, nas demandas dos clientes. \\
\hline $\begin{array}{l}\text { Entrevistado } \\
6\end{array}$ & $\begin{array}{l}\text { Sim, no processo de pagamento de boletos e solução de } \\
\text { problemas. }\end{array}$ \\
\hline $\begin{array}{l}\text { Entrevistado } \\
7\end{array}$ & Sim, no tempo de espera. \\
\hline $\begin{array}{l}\text { Entrevistado } \\
8\end{array}$ & Sim, na solução de problemas. \\
\hline $\begin{array}{l}\text { Entrevistado } \\
9\end{array}$ & Sim, na agilidade da fila. \\
\hline $\begin{array}{l}\text { Entrevistado } \\
10\end{array}$ & Sim, solução de demandas de clientes de outras agências. \\
\hline $\begin{array}{l}\text { Entrevistado } \\
11\end{array}$ & Sim, solução de problemas e pedidos de cartão. \\
\hline $\begin{array}{l}\text { Entrevistado } \\
12\end{array}$ & Sim, tempo de fila. \\
\hline $\begin{array}{l}\text { Entrevistado } \\
13\end{array}$ & Sim, na agilidade para solução de demandas. \\
\hline $\begin{array}{l}\text { Entrevistado } \\
14\end{array}$ & Sim, para solução de problemas. \\
\hline $\begin{array}{l}\text { Entrevistado } \\
15\end{array}$ & Na maioria das vezes sim, no tempo de fila. \\
\hline
\end{tabular}




\begin{tabular}{|l|l|}
$\begin{array}{l}\text { Entrevistado } \\
16\end{array}$ & Sempre, no tempo de espera. \\
\hline $\begin{array}{l}\text { Entrevistado } \\
17\end{array}$ & Sim, para pedidos de cartões novos e solução de problemas. \\
\hline $\begin{array}{l}\text { Entrevistado } \\
18\end{array}$ & Sim, na satisfação do cliente. \\
\hline $\begin{array}{l}\text { Entrevistado } \\
19\end{array}$ & Sim, tempo de fila. \\
\hline $\begin{array}{l}\text { Entrevistado } \\
20\end{array}$ & Sim, na agilidade e satisfação. \\
\hline
\end{tabular}

Observa-se que é unânime a percepção de que as mudanças nos processos interferem no atendimento aos clientes, segundo os entrevistados. As interferências por eles identificadas foram relacionadas ao tempo de espera na fila, agilidade para solução de problemas e demandas dos clientes, a satisfação dos clientes, além de pedidos de cartões novos e solução de problemas relacionados às contas dos clientes. Podemos identificar que as mudanças ocorridas no aspecto ostensivo das rotinas geram impacto no desempenho da rotina, o que mostra como a dinâmica de mudança das rotinas está relacionada à interação entre os aspectos ostensivo e performativo das rotinas organizacionais (FELDMAN; PENTLAND, 2003).

Com tantas mudanças que ocorrem na rotina desses profissionais, é importante sabermos como se dá o processo de aprendizagem, uma vez que há um novo procedimento (processo) a ser inserido no dia a dia dos bancários. Por esse motivo, segue abaixo o Quadro 3, onde podemos observar de que forma se dá a aprendizagem.

\section{Quadro 3 - Entrevista}

\begin{tabular}{|l|l|}
\hline Pergunta & $\begin{array}{l}\text { Quando uma nova mudança é implementada, como se dá a } \\
\text { aprendizagem? }\end{array}$ \\
\hline $\begin{array}{l}\text { Entrevistado } \\
1\end{array}$ & Através de cursos online. \\
\hline $\begin{array}{l}\text { Entrevistado } \\
2\end{array}$ & Através de cursos online e presencial às vezes. \\
\hline $\begin{array}{l}\text { Entrevistado } \\
3\end{array}$ & $\begin{array}{l}\text { Com cursos online temos as informações e no dia a dia se } \\
\text { aprende. }\end{array}$ \\
\hline
\end{tabular}




\begin{tabular}{|l|l|}
$\begin{array}{l}\text { Entrevistado } \\
4\end{array}$ & Aprendizagem se dá na prática. \\
\hline $\begin{array}{l}\text { Entrevistado } \\
5\end{array}$ & Online e no dia a dia. \\
\hline $\begin{array}{l}\text { Entrevistado } \\
6\end{array}$ & Na prática do dia a dia. \\
\hline $\begin{array}{l}\text { Entrevistado } \\
7\end{array}$ & Nos cursos temos as teorias, porém aprendemos com a prática. \\
\hline $\begin{array}{l}\text { Entrevistado } \\
8\end{array}$ & Aprendemos com nossos colegas. \\
\hline $\begin{array}{l}\text { Entrevistado } \\
9\end{array}$ & Por e-mail e com nossos supervisores. \\
\hline $\begin{array}{l}\text { Entrevistado } \\
10\end{array}$ & Na prática. \\
\hline $\begin{array}{l}\text { Entrevistado } \\
11\end{array}$ & No dia a dia com gerentes e colegas. \\
\hline $\begin{array}{l}\text { Entrevistado } \\
12\end{array}$ & Em reuniões mensais. \\
\hline $\begin{array}{l}\text { Entrevistado } \\
13\end{array}$ & Em treinamento às vezes presencial, às vezes online. \\
\hline $\begin{array}{l}\text { Entrevistado } \\
14\end{array}$ & Na prática. \\
\hline $\begin{array}{l}\text { Entrevistado } \\
15\end{array}$ & Durante o cotidiano com os colegas. \\
\hline $\begin{array}{l}\text { Entrevistado } \\
16\end{array}$ & No dia a dia e com os superiores. \\
\hline $\begin{array}{l}\text { Entrevistado } \\
17\end{array}$ & Cursos online e na prática. \\
\hline $\begin{array}{l}\text { Entrevistado } \\
18\end{array}$ & Cursos presenciais e na prática. \\
\hline $\begin{array}{l}\text { Entrevistado } \\
19\end{array}$ & Por e-mail e no dia a dia. \\
\hline $\begin{array}{l}\text { Entrevistado } \\
20\end{array}$ & No dia a dia com meus superiores e colegas. \\
\hline
\end{tabular}

De acordo com a opinião dos funcionários, a aprendizagem de um processo novo é realizada em cursos on-line, por e-mail e, principalmente, na prática com seus colegas de trabalho. Apesar da existência de artefatos utilizados pelo Banco, tanto para a divulgação das mudanças, quanto para a aprendizagem - artefatos que podem ser conceituados por D'ADDERIO (2011) 
como diferentes ferramentas, e-mails, documentos, computadores e regras -, a maioria dos entrevistados cita que é na prática que de fato se aprende em como realizar o procedimento com sucesso.

Podemos observar, que a aprendizagem citada pela colaboradora é a ativa, onde o indivíduo realiza tarefas do dia a dia, como ler e-mail e usar sua experiência para atualizar os conhecimentos prévios (GUNSS, 1998).

\footnotetext{
"Geralmente chega um e-mail informando da mudança com as novas regras, conversamos com a equipe e tentamos inserir no dia a dia" Entrevistado 12.
}

Conforme a fala do Entrevistado 4, podemos observar que as aprendizagens abordadas por ele são; sistêmica, de tarefas e por compartilhamento, uma vez que na fala dele existem esses três conceitos, que dizem a respeito do desempenho das tarefas, observação de processos coletivos e individuais, e o compartilhamento de novas habilidades (GUNSS 1998).

\footnotetext{
"A aprendizagem se dá no dia a dia com nossos pares e parceiros, obtemos as regras no sistema e discutimos entre nós e durante o dia tiramos dúvidas uns com os outros" - Entrevistado 4.
}

O processo de aprendizagem, segundo BARNEY (2001), vem para realizar novas metas, para inovar alguns fatores (com ajuda da tecnologia), mudando assim as rotinas já existentes e o comportamento do colaborador perante os clientes.

Para que a análise ficasse completa foi perguntado aos colaboradores do Itaú qual seria a nota atribuída ao atendimento da empresa aos seus clientes, de uma forma geral. Seguem abaixo as notas atribuídas por eles. 
Quadro 4 - Entrevista

\begin{tabular}{|c|c|}
\hline Pergunta & $\begin{array}{l}\text { De } 0 \text { a } 10 \text { qual a nota que você daria para o atendimento da } \\
\text { sua empresa? }\end{array}$ \\
\hline $\begin{array}{l}\text { Entrevistado } \\
1\end{array}$ & 8 \\
\hline $\begin{array}{l}\text { Entrevistado } \\
2\end{array}$ & 7 \\
\hline $\begin{array}{l}\text { Entrevistado } \\
3\end{array}$ & 8 \\
\hline $\begin{array}{l}\text { Entrevistado } \\
4\end{array}$ & 8 \\
\hline $\begin{array}{l}\text { Entrevistado } \\
5\end{array}$ & 9 \\
\hline $\begin{array}{l}\text { Entrevistado } \\
6\end{array}$ & 8 \\
\hline $\begin{array}{l}\text { Entrevistado } \\
7\end{array}$ & 9 \\
\hline $\begin{array}{l}\text { Entrevistado } \\
8\end{array}$ & 8 \\
\hline $\begin{array}{l}\text { Entrevistado } \\
9\end{array}$ & 8 \\
\hline \begin{tabular}{|l|} 
Entrevistado \\
10
\end{tabular} & 8 \\
\hline $\begin{array}{l}\text { Entrevistado } \\
11\end{array}$ & 9 \\
\hline $\begin{array}{l}\text { Entrevistado } \\
12\end{array}$ & 8 \\
\hline $\begin{array}{l}\text { Entrevistado } \\
13\end{array}$ & 8 \\
\hline $\begin{array}{l}\text { Entrevistado } \\
14\end{array}$ & 7 \\
\hline $\begin{array}{l}\text { Entrevistado } \\
15\end{array}$ & 8 \\
\hline $\begin{array}{l}\text { Entrevistado } \\
16\end{array}$ & 9 \\
\hline \begin{tabular}{|l|} 
Entrevistado \\
17
\end{tabular} & 9 \\
\hline $\begin{array}{l}\text { Entrevistado } \\
18\end{array}$ & 8 \\
\hline $\begin{array}{l}\text { Entrevistado } \\
19\end{array}$ & 8 \\
\hline
\end{tabular}


É possível observar que a nota mais citada foi oito. Isso nos mostra que mesmo com todas as mudanças e desafios atribuídos ao atendimento, os funcionários ainda assim acham que sua empresa presta um serviço de qualidade.

Durante as entrevistas, foi comum como justificativa da nota oito o fato de, no setor bancário, o Itaú ser um dos melhores prestadores de serviço. Isso nos mostra que as notas atribuídas foram em comparação ao mesmo serviço prestado pelos concorrentes.

Outra pergunta realizada nas entrevistas - "Já recebeu alguma reclamação referente ao atendimento, que poderia ter sido evitada se houvesse um processo mais alinhado e eficiente? Caso tenha recebido reclamação, o que aprendeu com isso? Esse fato gerou alguma mudança no procedimento?" - obteve a resposta "sim" de todos os entrevistados. Alguns citaram a situação de tempo de fila, que poderia ter um tempo menor, caso os processos fossem menos burocráticos e mais ágeis, outros disseram que as reclamações são referentes a processos que mudam, como, por exemplo, uma conta que não é mais paga no terminal de caixa. Tais mudanças afetam diretamente a relação do colaborador com o cliente.

Em outra pergunta feita durante a pesquisa - "Você percebeu que ao longo dos anos as mudanças nos processos, vêm melhorando ou piorando o atendimento?" - a grande maioria disse que vem melhorando de imediato a implementação da mudança, exceto o Entrevistado 12, que disse: "No primeiro momento piora, pois o cliente não entende ou não sabe da mudança, mas ao longo tempo melhora, pois torna os clientes mais independentes e podem resolver demandas foram das agencia".

Para a pergunta - "Já ficou sem atender uma demanda do cliente por causa de algum procedimento interno? Se sim, cite alguns" - todos disseram "Sim", e citaram, principalmente, o fato de não conseguirem resolver demandas de clientes de outras agências, como, por exemplo, mudança de endereço, pedido de cartão novo para endereço certo, extrato e estornos, além de contas 
de concessionarias (água, luz, telefone) que não são pagas nos terminais de caixa, o que deixa o cliente bastante incomodado e insatisfeito.

Por fim, para outra pergunta feita - "Recebeu algum elogio por causa do processo utilizado para atendimento? Se sim, cite alguns" -, dos vintes colaboradores entrevistados, doze disseram que já receberam elogios, principalmente porque atenderam o cliente rapidamente, fazendo com que ele ficasse pouco tempo na fila. Outro tipo de elogio citado foi resolver o problema em relação ao cliente que não consegue receber seu cartão da conta. Para essa demanda, foi implementado um novo processo que consiste em liberar para o mesmo um cartão provisório que o possibilita utilizar a conta mesmo antes de seu cartão definitivo chegar. Para embasar essa pergunta, foi levado em consideração o aspecto performativo que podemos observar que nessa situação a ação do funcionário é fundamental para que possa acontecer o elogio, sendo assim e "ações específicas, realizadas por pessoas específicas, em lugares e tempos específicos" (FELDMAN; PENTLAND, 2003, p. 102. Tradução livre).

Todos os entrevistados sentiram, de alguma forma, que as mudanças nas rotinas organizacionais afetaram o atendimento aos clientes, principalmente quando as mudanças foram derivadas de alguma lei ou novas tecnologias. Os entrevistados também concordam que o atendimento do Banco Itaú é um dos melhores do mercado, pois de vinte entrevistas, treze deram nota oito, cinco deram nota nove e apenas dois deram nota sete.

Durante as entrevistas, eram comuns falas como essa do Entrevistado 3: "Nosso banco é nota oito, pois nesse setor bancário a prestação de serviço é bem ruim. Por esse motivo nos destacamos". 


\section{Considerações Finais}

O presente trabalho atingiu seu objetivo na medida em que identificou que as mudanças nas rotinas organizacionais afetam diretamente o atendimento aos clientes. Tais mudanças podem afetar positiva (novas tecnologias) ou negativamente (principalmente por novas legislações) a rotina do Banco.

Positivamente, quando há uma nova tecnologia que facilita ou torna o atendimento mais rápido, como dito pelo Entrevistado 1: "As novas tecnologias como a NPS (sistema onde o banco envia uma mensagem para o cliente perguntando sobre o atendimento) ajuda o gestor a orientar e disciplinar os funcionários para melhor atender ao publico". Nesse caso, a NPS além de mandar mensagem para o cliente, também gera um relatório para o gerente acompanhar as notas recebidas por cada colaborador. Essa ação afeta positivamente, uma vez que o gestor tem autonomia para ligar para o cliente e saber o motivo da nota, para assim sinalizar ao colaborador ou tomar providenciam cabíveis - tudo com o intuito de melhorar o atendimento prestado.

Negativamente, quando há uma atualização da lei que torna os procedimentos do banco mais burocráticos, como, por exemplo, citado na fala do Entrevistado 14:

"As legislações dificultam nosso atendimento tornando-o mais lento, como no caso de informe de valores para o Banco Centro em espécie".

Esse fato, afeta negativamente, pois todos os clientes que utilizam dinheiro em espécie, acima de dez mil, precisam fazer uma notificação quanto ao destino e origem dos recursos para o Banco Central, para prevenção à lavagem de dinheiro. Porém, esse procedimento é demorado e, geralmente, os clientes não querem dispor dessas informações, o que acaba impactando na rapidez da fila e na satisfação dos mesmos.

Por fim, podemos observar que a aprendizagem de novas rotinas se deu principalmente no dia a dia dos funcionários, havendo um norte por e-mail ou cursos online e colocando em prática, como dito a seguir: 
“Há uma comunicação por e-mail ou tem algum curso online, porém a aprendizagem se dá mesmo no dia a dia com meus pares e parceiros" - Entrevistado 7.

Podemos concluir que as mudanças nas rotinas organizacionais do Itaú vêm, ao longo dos anos, influenciando o atendimento aos clientes, e a aprendizagem de novas rotinas se dá principalmente no cotidiano, o que acaba afetando $\mathrm{o}$ atendimento também. Além disso, podemos perceber que os colaboradores veem o Banco de forma positiva, mesmo com todos esses desafios, frente aos demais existentes no setor bancário, que, como dito por eles, é um setor com um atendimento precário ao público.

A partir dessas conclusões, entende-se que este trabalho oferece uma contribuição para a gestão de agências bancárias, no que se refere às dinâmicas de mudanças nas rotinas relacionadas ao atendimento ao cliente, dando à empresa uma visão de como se podem melhorar os procedimentos internos a fim de obter a satisfação dos clientes, proporcionando a eles uma experiência positiva para se sobressair frente aos concorrentes. Esse trabalho contribui também para futuras pesquisas relacionadas a rotinas organizacionais no setor bancário, não somente as que impactam o atendimento ao cliente, como também aquelas que norteiam os funcionários, fornecedores e parceiros.

Para futuros estudos esse trabalho pode contribuir muito, porém há de serem levadas em consideração as condições atuais de tecnologia e legislação, pois há no futuro próximo uma expectativa de um novo olhar entre na relação do cliente com seu banco, devido ao conceito de open Banking que visa deixar os clientes com suas informações bancarias e usa-las conforme achar melhor por esse motivo a relação de vemos hoje será completamente alterada no futuro. 


\section{Referências Bibliográficas}

BARNEY, J.B. Resource-Based Theories of Competitive Advantage: A Ten Year Retrospective on the Resource-Based View. Journal of Management, 27, 2001.

BARRETO, M. Violência saúde e trabalho: uma jornada de humilhações. São Paulo: PUC - SP, 2006.

BECKER, M.C. Organizational routines: a review of the literature. Industrial and Corporate Change, v.13, n.4, p.643-677, 2004.

BRAVERMAN, H. (Trabalho e Capital Monopolista. 3. ed. São Paulo: LTC, 1987.

CHIAVENATO. Gestão de Pessoas: o novo papel dos recursos humanos nas organizações. Rio de Janeiro: Campus 2000.

D'ADDERIO, L. Artifacts At The Centre Of Routines: Performing The Material Turn In Routines Theory. J. Institutional Econom. v. 7(2), p. 197230, 2011.

DOSI, G., NELSON, R., \& WINTER, S. The nature and dynamics of organizational capabilities. Oxford, United Kingdom: OUP Oxford, 2000.

EDNILSON, E. Aprendizagem Organizacional: A organização que aprende. Disponível em

$<$ https://administradores.com.br/artigos/aprendizagem-organizacional-aorganizacao-que-aprende>. Acesso em 03 de novembro de 2019.

ELTZ, Fabio. Qualidade na comunicação: preparando a empresa para encantar o cliente. São Paulo: Casa da Qualidade, 1994. 
FABRíCIO, E. Revisão bibliográfica sobre assédio moral no trabalho: estado da arte da pesquisa brasileira. Brasília: UniCEUB, 2012.

FELDMAN, Martha S.; PENTLAND, Brian T. Reconceptualizing organizational routines as a source of flexibility and change. Administrative Science Quarterly, 48(1), 94-118, 2003.

FELDMAN, M. S. Routines as process: Past, present, and future. In J. Howard-Grenville, C. Rerup, A Langley, \& Tsoukas (Eds.), Organizational Routines: How They Are Created, Maintained, and Changed. Oxford University Press, 23-46, 2016.

FELDMAN, M. S., PENTLAND, B. T., D'ADDERIO, L., \& LAZARIC, N. Beyond routines as things: Introduction to the special issue on routine dynamics. Organization Science, (3), 505-513, 2016.

GUIMARÃES, Maria Isabel. 0 aprender nas rotinas organizacionais: 0 design thinking e a criação de rotinas guiadas por uma lógica de aprendizagem. Rio de Janeiro, 2018. Disponível em: <file://C:/Users/G1512942/Downloads/MarialsabelPGuimaraes_Certificada .pdf> Acesso em 09 de outubro de 2019.

GUNS, B. A organização que aprende rápido: seja competitivo utilizando o aprendizado organizacional. São Paulo: Futura, 1998.

HELOANI, J. R. Assédio Moral - Um ensaio sobre a expropriação da dignidade no trabalho. Revista de Administração de Empresas, São Paulo, v. 3, n. 1, jan. / jun. 2004.

KOTLER, Philip. Administração de Marketing. 10 ed. São Paulo: novo Milênio, 2000.

KOTLER, Philip \& ARMSTRONG, Gary. Princípios de Marketing. 5. ed. Rio de Janeiro: Prentice/Hall do Brasil. 1991. 
LAS CASAS, A. L. Plano de Marketing para micro e pequena empresa. São Paulo. Ed. Atlas, 1999.

MAGALHÃES, Luzia Eliana Reis; ORQUIZA, Liliam Maria. Metodologia do trabalho científico: elaboração de trabalhos. 1. ed. Curitiba: FESP, 2002.

MARTINS, Gilberto de Andrade. Estudo de Caso: uma estratégia de pesquisa. São Paulo: Atlas, 2006.

NOGUEIRA, Antônio. 0 conceito de rotinas em estudos organizacionais: comparação entre o paradigma funcionalista e a teoria da estruturação. Florianópolis, 2010. Disponível em: < anpad.org.br/admin/pdf/eneo611.pdf>. Acesso em 03 de novembro de 2019.

OLIVEIRA, Luciana. Atendimento Diferenciado ao Cliente. Disponível em <https://administradores.com.br/artigos/atendimento-diferenciado-aocliente>. Acesso em 02 de novembro de 2019.

PENTLAND, Brian T.; FELDMAN, Martha S., Organizational Routines as Units of Analysis. Industrial and Corporate Change, 14(5), 793-815, 2005.

PINHEIRO, Roberto Meireles; CASTRO, Guilherme Caldas de; SILVA, Helder Haddad; et al. Consumidor e pesquisa de mercado. Rio de Janeiro: FGV, 2004.

PONTES, Elivelton. Aprendizagem Organizacional: 0 que é e como aplicar. Paraná, 2018. Disponível em: <https://eadbox.com/aprendizagemorganizacional/>. Acesso em 05 de novembro de 2019.

SAMPAIO, Pedro. Rotinas Organizacionais: Um Estudo Bibliográfico. Rio de Janeiro, 2016. Disponível em: <http://www.pucrio.br/pibic/relatorio_resumo2016/relatorios_pdf/ccs/ADM/ADM-

Pedro\%20Renato\%20Rodrigues\%20Sampaio.pdf>. Acesso em 10 de novembro de 2019. 
SANTOS, Eliane; BORGES, Gustavo; GIACOMELLI, William. Determinantes da Desmotivação no Trabalho: Uma Investigação Teórica e Empírica. Roraima, $2016 . \quad$ Disponível em: <https://revista.ufrr.br/adminrr/article/viewFile/2602/pdf>. Acessado em: 05 de novembro de 2019.

SANTOS, Mariana; TORRES, Kelly; SILVA, Leonardo; BORBA, Erika. Satisfação de Clientes: Análise do atendimento Prestado Pelas Empresas no Comércio de São João Del Rei - MG. São João Del Rei, $2016 . \quad$ Disponível em: <https://www.aedb.br/seget/arquivos/artigos17/542539.pdf>. Acesso em 05 de novembro de 2019.

VERGARA, Sylvia Constant. Projetos e relatórios de pesquisa em administração. 7. ed. São Paulo: Atlas, 2006. 


\section{Apêndice}

1 - Qual seu nome e cargo? Há quantos anos trabalha na empresa?

2 - Você pode me contar como é a sua rotina de atendimento ao cliente?

3 - Você percebe mudanças na sua rotina do dia-a-dia ao longo dos anos em relação ao atendimento do cliente?

4 - Essas mudanças nos processos interferem no atendimento ao cliente? Quais interferências você identifica?

5 - Você percebeu que ao longo dos anos as mudanças nos processos, vêm melhorando ou piorando o atendimento?

6 - Quando uma nova mudança é implantada como se dá a aprendizagem do novo método processo? Você pode me contar uma experiência de aprendizagem sua, nesse sentido?

7 - Já ficou sem atender uma demanda do cliente por causa de algum procedimento interno? Se sim, cite alguns.

8 - Já recebeu alguma reclamação referente ao atendimento que podia ter sido evitada se houvesse um processo mais alinhado e eficiente? Caso tenha recebido reclamação, o que aprendeu com isso? Esse fato gerou alguma mudança no procedimento?

9 - Recebeu algum elogio por causa do processo utilizado para atendimento? Se sim, cite alguns.

10 - De 0 a 10 qual nota você daria quanto ao atendimento prestado por sua empresa? Essa nota poderia melhorar se os processos fossem mais eficazes? 